\title{
Management of a Case of Internal Root Resorption: Case Report
}

\author{
Mirela Marinova-Takorova ${ }^{1}$, Elitsa Deliverska ${ }^{2}$, Velislava Mazneva ${ }^{3}$ \\ ${ }^{1}$ Department of Conservative Dentistry, Faculty of Dental Medicine, Medical University, Sofia, Bulgaria \\ ${ }^{2}$ Department of Surgery, Faculty of Dental Medicine, Medical University, Sofia, Bulgaria
}

\begin{abstract}
Internal root resorption is a pathological process, sequel of a chronic pulp inflammation. The aim of this case report is to describe the interdisciplinary treatment plan that was applied in a case of perforating internal root resorption. A 24-year-old patient presented to the clinic with complains that her front right incisor got slightly intruded two years after orthodontic treatment. The root canal system was accessed. A large zone of internal resorption with two perforating points (vetibularly and proximally) was observed in the cervical region of the incisor. The root canal was temporary filled with calcium hydroxide.The root was permanently filled with gutta-percha and a sealer till the level of the resorption area. A flap was elevated and the two perforated sites were visualized and filled with BioDentine. A composite veneer was placed in order to restore the esthetics. The success of the treatment of internal root resorption depends on the early diagnosis and initiation of endodontic treatment. In cases of perforating internal resorption a multidisciplinary approach, including endodontic treatment, surgical reconstruction of the root perforation and in some cases orthodontic extrusion should be applied.
\end{abstract}

Keywords: internal rootresorption

\section{Introduction}

Internal root resorption is a pathological process, sequel of a chronic pulp inflammation. It leads to loss of dentin, cement or even bone due to clastic cell activity. A layer of odontoblasts and predentin covers dentinand protects it [7]. Different ethiological factors could lead to damage of that layer and then odontoclasts may start resorbing dentin. Traumas, incipient or recurrent caries, heat generated during operative treatment, cracks, orthodontic treatment and idiopatic dystrophic pulpal changes are cited as ethiological factors for internal root resorption [8]. The cells responsible for the internal root resorption are muclinucleated giant cells called odontoclasts. According to somerecent theories dendric cells are precursors who could convert into odontoclaststhat move to the sites of irritation by proinflamatory cytokines and then start the resorbing process [12]. Those cells colonize the unprotected dentin. If there is no continuing irritation this process could end spontaneously and then no treatment is needed. If there is a stimulation factor present and the blood supply is sufficient they start and continue resorbing it $[3,7,11]$.

The aim of this case report is to describe the interdisciplinary treatment plan that was applied in a case of perforating internal root resorption.

\section{Case Report}

A 24-year-old patient presented to the clinic with complains that her front right incisor got slightly intruded two years after orthodontic treatment (fig. 1). There were no caries lesions or restorations on the tooth and there was no data for acute trauma. On clinical examination the tooth had a slight pinkish hue in the cervical region. There was observed slight tenderness on axial percussion and mild mobility. The marginal gingiva was swollen and there was found a periodontal pocket $4 \mathrm{~mm}$ deep on the vestibular tooth surface on probing. The pulp test response was at $35 \mu \mathrm{A}$. Radiolucency in the cervical region was observed on the conventional radiographic examination using parallel technique (fig. 2). After retraction of the gingiva a small vestibular perforation with granulation tissue was seen (fig. $3)$.

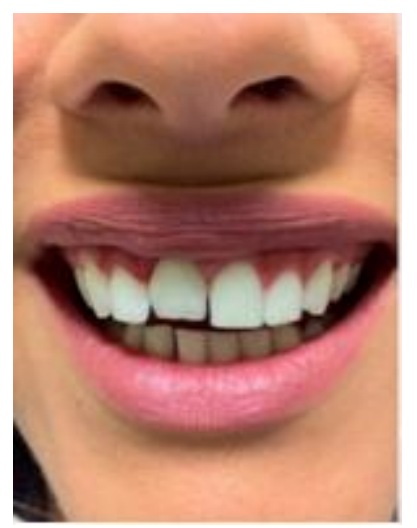

Figure 1: Initial view of patient dentition

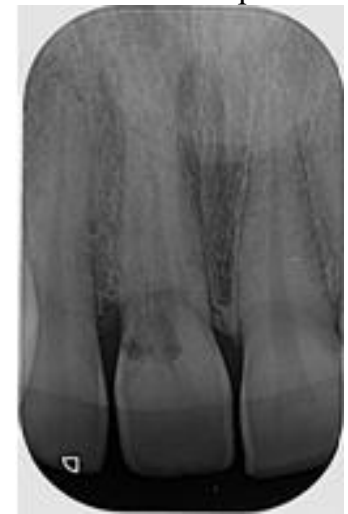

Figure 2: Preliminary X-ray examination

Verbal and written conceits were taken from the patient. After the placement of a rubber dam the root canal system was accessed. The pulp was partially vital. A large zone of internal resorption was observed in the cervical region of the 


\section{International Journal of Science and Research (IJSR) \\ ISSN (Online): 2319-7064}

Index Copernicus Value (2013): 6.14 | Impact Factor (2015): 6.391

incisor. There were two points in which the resorption perforated - one on the vestibular surface of the root (the one that was diagnosed during the preliminary exam) and one on the distal root surface (fig. 4). Working length was determined and canal instrumentation was performed till file F2 (Pro Taper Universal, Mailefer). Irrigation was performed with $2,5 \%$ sodium hypochloride.

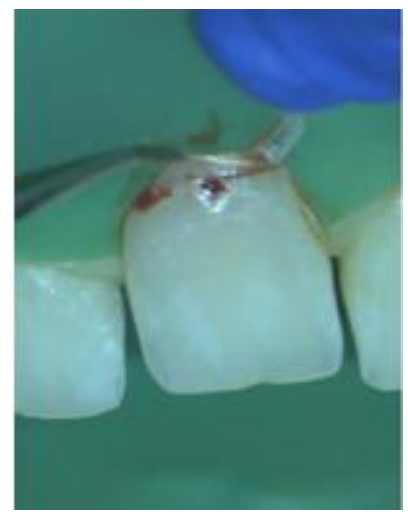

Figure 3: A view of a vestibular perforation

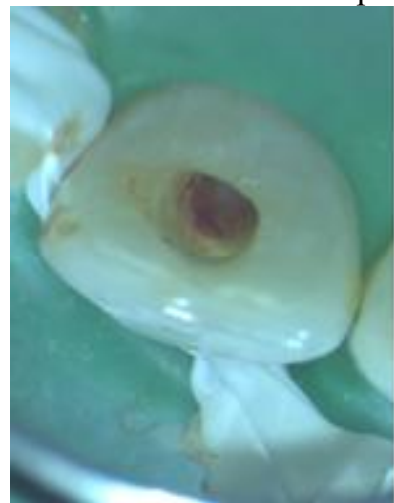

Figure 4: View of the perforation from the pulp chamber

Permanent seal of the root canal was not performed because of continuous exudation and bleeding. The root canal was filled with calcium hydroxide and the access cavity was closed with glass-ionomer cement. The calcium hydroxide was changed after three weeks. There was still little exudation from the perforation sites so calcium hydroxide temporary filling was placed again into the root canal. The root was permanently filled with gutta-percha and a sealer till the level of the resorption area (fig. 5), after enlargement of the root canal till F3 (ProTaper Universal). A fiber post was placed and the endodontic access cavity was restored with composite material. A flap was elevated and the two perforated sites were visualized (fig. 6).

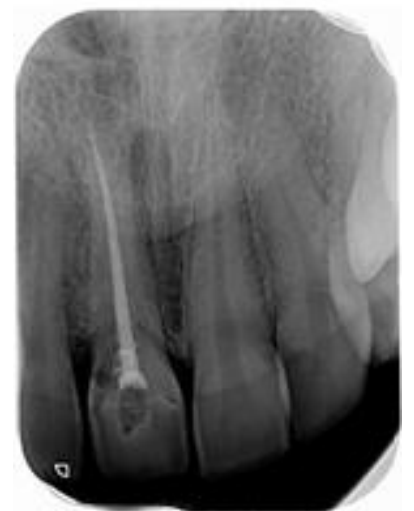

Figure 5: Control X-ray of the filled root canal

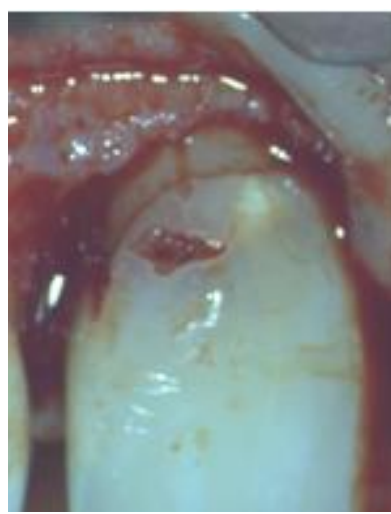

Figure 6: View of the vestibular and proximal perforation after flap elevation

The perforations were curetted and enlarged (fig. 7). They were treated with $90 \%$ aqueous solution of trichloroacetic acid. The perforations were filled with BioDentine and the flap was repositioned and sutured (fig. 8 and fig. 9). The patient was prescribed analgesics and antibiotics for seven days after surgery. One week after the operation the sutures were removed. Then a composite veneer was placed in order to restore the height of the crown of the tooth (fig. 10).

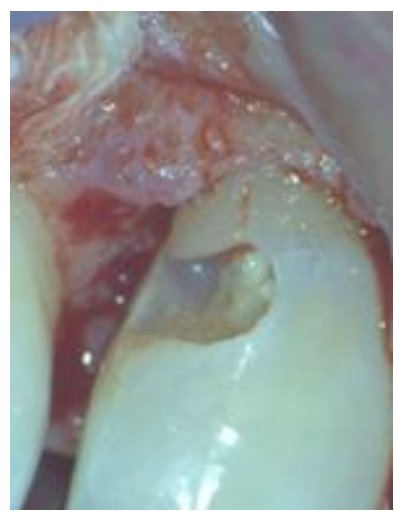

Figure 7: Connection of the two perforations after removal of granulating tissue

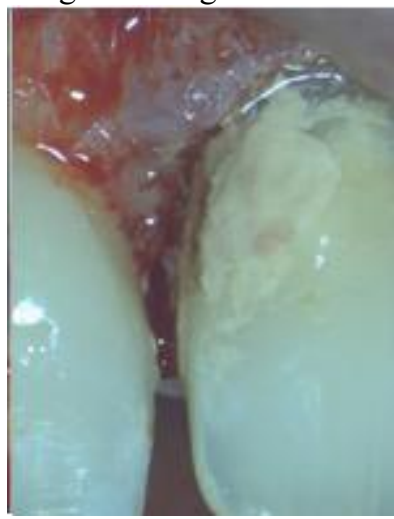

Figure 8: Restoration of the defect with BioDentine

Volume 5 Issue 7, July 2016

www.ijsr.net

Licensed Under Creative Commons Attribution CC BY 


\section{International Journal of Science and Research (IJSR) \\ ISSN (Online): 2319-7064}

Index Copernicus Value (2013): 6.14 | Impact Factor (2015): 6.391

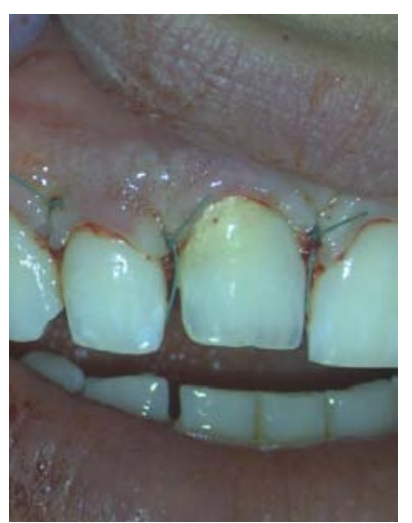

Figure 9: Repositioned flap

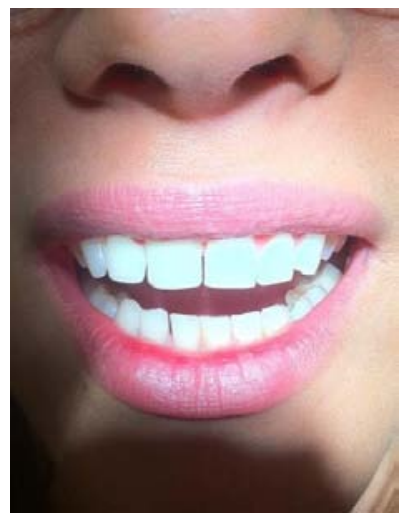

Figure 10: Final esthetic restoration

\section{Discussion}

Root resorption is a serious dental complication, which when not diagnosed and treated in time might lead to tooth loss. The resorption process in the presented case involved the cervical region of the tooth. The patient gave data that she has had an orthodontic treatment two years ago. There is data in the literature that orthodontic treatment causes degenerative changes in teeth with completed apical formation [4]. This usually leads to apical and rarely cervical resorption $[10,15]$. In the presented case we had internal resorption which is usually a result of trauma, caries, pulp capping, extreme heat, cracks $[1,13,14]$. We had none of the mentioned etiological factors, typical for internal root resorption.

The patient presented with a symptom that is typical for internal resorption localized in the coronal region - pinkish hue in the cervical region - the so called 'pink spot". However this symptom is typical for the invasive cervical resorption too [9]. Internal root resorption could be mistaken with the cervical root resorption on the X-ray exam too. They could be differentiatedby change of the angle of the Xray. In cases with internal resorption usually no bone changes are detected except when the defect is perforating.

The prognosis of teeth with internal root resorption depends on the size of the lesion. The treatment includes root canal therapy that leads to interruption of the resorptive process because of the removal of the clastic cells. When the size of the defect is small the chemomechanical root canal treatment is usually sufficient. Most of the authors recommend $2.5 \%$ solution of sodium hypochlorite $[1,2,13]$, although some have used higerconcentratios[9, 14]. Granulating tissue cannot always be removed completely when the size of the resorbed area is too big. Then the bleeding and exudation cannot be stopped. Temporary application of calcium hydroxide for approximately one week is recommended in these cases [5].

If the internal resorption is perforating and the defect is under thebone some authors recommend the placement of calcium hydroxide for a longer period [15], or the use of MTA $[6,13,14]$.

We have placed a post in the root canal and filled the resorptive defect with composite material in order to strengthen the remaining dental tissues, according to the recommendations of some authors $[1,5]$.

\section{Conclusion}

The success of the treatment of internal root resorption depends on the early diagnosis and initiation of endodontic treatment. In cases of perforating internal resorption a multidisciplinary approach, including endodontic treatment, surgical reconstruction of the root perforation and in some cases orthodontic extrusion should be applied.

\section{References}

[1] Cury P.R., M.T. Martins, E.A.Sallum, N.S. De Araujo: Root resorption and ankylosis associated with guided tissue regeneration; J Am Dent Assoc 2005 136(3) 337 341

[2] De FigueiredoM.A., J.A. De Figueiredo, S. Porter: Root resorption associated with mandibular bone erosion in a patient with scleroderma; J Endod 2008 34(1)102-103

[3] Fuss Z., I. Tsesis, S. Lin: Root resorption - diagnosis, classification and treatment choices based on stimulation factors; Dent Traumatol 2003 19(4) 175-182

[4] HamiltonR.S.,J. L. Gutmann: Endodontic orthodontic relationships: a review of integrated treatment planning chalanges; IntEndod J; 1999 32(5) 343-360

[5] Hommez G.M., H.A.Browaeys, R.J. De Moor: Surgical root restoration after external inflammatory root resorption: A case report; J Endod 2006 32(8) 789-801

[6] Hsien H.C., Y.A. Cheng, Y.L. Le, W.H. Lan, C.P. Lin: Repair of perforating internal resorption with mineral trioxide aggregate: a case report; J Endod 2003 29(8) 538-539

[7] Kanas R.J., S. J. Kanas: Dental Root Resorption: A Review of the Literature and a Proposed New Classification; Compendium of Continuing Education in Dentistry 2011 32(3): 38-52

[8] Patel S., D.Ricucci, C.Durac, F. Tay:Intarnal root resorption: a review; JEndod 2010 36(7): 1107-1121

[9] Perlea P., C.C. Nistor, M.G. Iliescu, A.A. Iliescu: The use of cone beam computed tomography in the diagnosis and management of internal root resorption associated with chronic apical periodontitis: a case report; Rom J MorpholEmbriol 2015 56(1): 223-227

[10]Pizzo G., M.E. Licata, R. Guiglia, R. Giuliana. Root resorption and orthodontic treatment. Minerva Stomatologica 2007 56(1): 31-44

\section{Volume 5 Issue 7, July 2016




\section{International Journal of Science and Research (IJSR) \\ ISSN (Online): 2319-7064}

Index Copernicus Value (2013): 6.14 | Impact Factor (2015): 6.391

[11] Ramazni M., S. Asgary, N.Zaranejad, J.Mehrani: Interdisciplinary approach for management of iatrogenic internal root resorption: a case report;Iran Endod J 2015 10(4) 71-74

[12] Regan J.D., D.E. Witherspoon, D.M. Foyle: Surgical repair of root and tooth perforations; Endodontic topics 2005 11(1)152-178

[13] Savage R.R., G.K. Vincent: Restoration and retention of maxillary anteriors with severe root resorption; J Am Dent Assoc 2002 133(1)67-71

[14] Umashetti G., U. Hoshing, S. Patil, N. Ajagaonkar: Management of inflammatory internel root resorption with biodentine and thermoplasticised gutta-percha; Case Reports in Dentistry 2015, article ID 452609, 4pages

[15] Villa P.A., G. Oberti, C.A. Moncada, O.Vasseur, A. Jaramillo, D. Tobon, J.A. Agudelo: Pulp-dentine complex changes and root resorption during intrusive orthodontic tooth movement in patients prescribed nabumetone. Journal of endodontics; 2004 31(1): 61-65

\section{Author Profile}

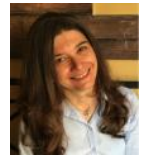

Mirela Marinova-Takorova, $\mathrm{DMD}, \mathrm{PhD}$, Assistant Professor, Department of Conservative Dentistry, Faculty of dental Medicine, Medical University Sofia, Bulgaria since 2003. She has been teaching students in clinics and preclinics. Her $\mathrm{PhD}$ thesis is 'Root caries lesions. Materials used in their treatment'. She gives lectures and trainings on microscopy use in the dental field.

Elitsa Deliverska DMD, PhD, Associate Professor, Department of Oral and Maxillofacial Surgery, Faculty of dental Medicine, Medical University - Sofia, Bulgaria

Velislava Mazneva. Private practice practitioner, Sofia, Bulgaria 